\title{
A systematic review of the epidemiology of carbapenem-resistant Enterobacteriaceae in the United States
}

\author{
Daniel J. Livorsi ${ }^{1,2^{*}+} \mathbb{D}$, Margaret L. Chorazy ${ }^{3+}$, Marin L. Schweizer ${ }^{1,2}$, Erin C. Balkenende ${ }^{1}$, Amy E. Blevins ${ }^{4,5}$,
} Rajeshwari Nair ${ }^{1,2}$, Matthew H. Samore ${ }^{6,7}$, Richard E. Nelson ${ }^{6,7}$, Karim Khader ${ }^{6,7}$ and Eli N. Perencevich ${ }^{1,2}$

\begin{abstract}
Background: Carbapenem-resistant Enterobacteriaceae (CRE) pose an urgent public health threat in the United States. An important step in planning and monitoring a national response to CRE is understanding its epidemiology and associated outcomes. We conducted a systematic literature review of studies that investigated incidence and outcomes of CRE infection in the US.

Methods: We performed searches in MEDLINE via Ovid, CDSR, DARE, CENTRAL, NHS EED, Scopus, and Web of Science for articles published from 1/1/2000 to 2/1/2016 about the incidence and outcomes of CRE at US sites.

Results: Five studies evaluated incidence, but many used differing definitions for cases. Across the entire US population, the reported incidence of CRE was 0.3-2.93 infections per 100,000 person-years. Infection rates were highest in long-term acute-care (LTAC) hospitals. There was insufficient data to assess trends in infection rates over time. Four studies evaluated outcomes. Mortality was higher in CRE patients in some but not all studies.

Conclusion: While the incidence of CRE infections in the United States remains low on a national level, the incidence is highest in LTACs. Studies assessing outcomes in CRE-infected patients are limited in number, small in size, and have reached conflicting results. Future research should measure a variety of clinical outcomes and adequately adjust for confounders to better assess the full burden of CRE.
\end{abstract}

Keywords: Carbapenem-resistant Enterobacteriaceae, United States, Epidemiology

\section{Background}

The Centers for Disease Control and Prevention (CDC) in the United States has deemed carbapenem-resistant Enterobacteriaceae (CRE) an urgent public health threat that requires immediate and aggressive action [1]. The reason for this urgency is clear: CRE infections are resistant to nearly all antibiotics and are associated with poor clinical outcomes [2].

Carbapenem-resistance in Enterobacteriaceae can result from a variety of mechanisms [3]. In the US, CRE isolates commonly produce carbapenemases; these enzymes are

\footnotetext{
* Correspondence: daniel-livorsi@uiowa.edu

'Equal contributors

${ }^{1}$ Center for Comprehensive Access Delivery \& Research, lowa City VA Health Care System, lowa City, USA

${ }^{2}$ Department of Internal Medicine, Carver College of Medicine, University of lowa, lowa City, USA

Full list of author information is available at the end of the article
}

carried on plasmids and can be easily shared with other gram-negative bacteria. The Klebsiella pneumoniae carbapenemase (KPC) was first recognized in North Carolina in 1996 and has since spread around the world [4]. Other examples of carbapenemases include the New Delhi Metallo- $\beta$-lactamase (NDM), Verona Integron-encoded Metallo- $\beta$-lactamase (VIM), Oxacillinase-48-type carbapenemases (OXA-48), and imipenemase (IMP).

CRE infections are typically seen in patients with prior healthcare exposure, and medical devices are a common risk factor for CRE acquisition [5]. According to 20092010 data from the National Healthcare Safety Network (NHSN), 20\% of hospitals reporting central line-associated bloodstream infections (CLABSIs) or catheter-associated urinary tract infections (CAUTIs) due to Klebsiella spp. reported at least 1 carbapenem-resistant strain [6]. In 2013,

(c) The Author(s). 2018 Open Access This article is distributed under the terms of the Creative Commons Attribution 4.0 International License (http://creativecommons.org/licenses/by/4.0/), which permits unrestricted use, distribution, and reproduction in any medium, provided you give appropriate credit to the original author(s) and the source, provide a link to the Creative Commons license, and indicate if changes were made. The Creative Commons Public Domain Dedication waiver (http://creativecommons.org/publicdomain/zero/1.0/) applies to the data made available in this article, unless otherwise stated. 
an outbreak of NDM-producing Escherichia coli was associated with duodenoscopes at an Illinois hospital [7].

Despite ongoing control efforts, CRE has become prevalent in several US regions, including Orange County, California and the Chicago metropolitan area [8, 9]. CRE has been endemic in the New York/New Jersey area since the early 2000s [10]. According to the 2013 CDC Antibiotic Resistance Threat Report, there are 9000 healthcareassociated CRE infections every year in the US, resulting in 600 deaths (mortality rate 6.6\%) [1]. However, such a low proportion of deaths may be an underestimation due to how infections were defined.

The CDC has published toolkits on preventing the spread of CRE within and between healthcare facilities $[3,11]$. While these toolkits have aided efforts at CRE prevention, a better understanding of the epidemiology and burden of CRE is critical to encourage increased investments in the study and prevention of these pathogens. To this end, we conducted a systematic review and evaluation of studies which investigated incidence and outcomes of CRE infection at US sites.

\section{Methods}

\section{Search strategy}

This systematic literature review was performed according to the MOOSE and PRISMA guidelines [12, 13]. An experienced health sciences librarian conducted systematic searches in MEDLINE via Ovid, Cochrane Database of Systematic Reviews via Wiley (CDSR), Database of Abstracts of Reviews of Effects via Wiley (DARE), Cochrane Central Register of Controlled Trials via Wiley (CENTRAL), NHS Economic Evaluation Database (NHS EED) via Wiley, Scopus, and Web of Science. We searched for articles published between the dates January 1, 2000 and February 1, 2016. Search terms included Medical Subject Headings (MeSH) and keywords for carbapenem resistance, Enterobacteriaceae, adverse events, incidence, prevalence, and economics. Additional file 1 includes a description of the complete search strategy. We reviewed the reference lists from each article to identify additional studies.

\section{Inclusion and exclusion criteria}

Studies were included if they (1) were conducted in the United States; (2) evaluated incidence of CRE or outcomes attributed to CRE infections including mortality, length of stay (LOS), discharge to a long-term acute-care (LTAC) hospitals, readmission, recurrence, and costs; (3) included at least 7 study sites (incidence studies only); and (4) used either the CDC's original or revised definition for CRE [3, 11]. In the original definition, an Enterobacteriaceae isolate qualified as CRE if it was non-susceptible to imipenem, meropenem or doripenem AND resistant to all of the following third-generation cephalosporins: ceftriaxone, cefotaxime and ceftazidime
[11]. In the revised 2015 definition, an Enterobacteriaceae isolate qualified as CRE if it was resistant to imipenem, meropenem, or doripenem, (minimum inhibitory concentration $[\mathrm{MIC}] \geq 4 \mathrm{mcg} / \mathrm{mL}$ ) OR resistant to ertapenem $(\mathrm{MIC} \geq 2 \mathrm{mcg} / \mathrm{mL}$ ) OR had documented production of a carbapenemase [3]. In 2010, the Clinical and Laboratory Standards Institute (CLSI) lowered the breakpoints for carbapenems by a factor of 4 , so in reviewing each study, we made note of which version of the CLSI breakpoints was used.

We excluded studies that (1) were less than 6 months in duration; (2) used International Classification of Diseases Clinical Modification diagnosis codes to define CRE infections; (3) used surveillance cultures from nonsterile body sites to detect CRE; (4) did not have a denominator or control group; (5) took place during an outbreak; (6) were mathematical models; (7) did not contain original data; and (8) were published in a language other than English. We excluded studies evaluating LOS or costs if they did not measure post-infection LOS or costs, or if they did not match infected cases and uninfected controls on time at risk (time from admission to infection for cases, time from admission to discharge for uninfected controls) or did not match on propensity scores.

\section{Data extraction and quality assessment}

One investigator (MLC) reviewed the titles and abstracts of all articles for inclusion and exclusion criteria. Two of four reviewers (MLC, RN, ENP, MLS) independently abstracted data for each included study. Disagreements between reviewers were resolved by consensus.

The reviewers abstracted data on the following items: study design, population and setting, location, definition of CRE infection, incidence data, prevalence data, mortality, LOS, discharge to LTAC, readmission, recurrence, and cost. Additional data were collected regarding tests used to identify CRE infection, identification of different species that were identified as CRE, and definitions of resistance.

Risk of bias was assessed using the Newcastle-Ottawa scale for included studies [14].

\section{Results}

We screened 18,178 unique studies for eligibility (Fig. 1). Nine studies were eligible for inclusion, including 5 multicenter studies reporting the incidence of CRE infections [15-19] and 4 studies (2 multicenter and 2 single center) evaluating relevant outcomes [20-23]. Included studies were of moderate-to-high risk of bias according to the Newcastle-Ottawa tool (Table 1). Included studies had low risk of bias when it came to representativeness and ascertainment of CRE infected patients and controls. However, most of the included studies had high risk of 


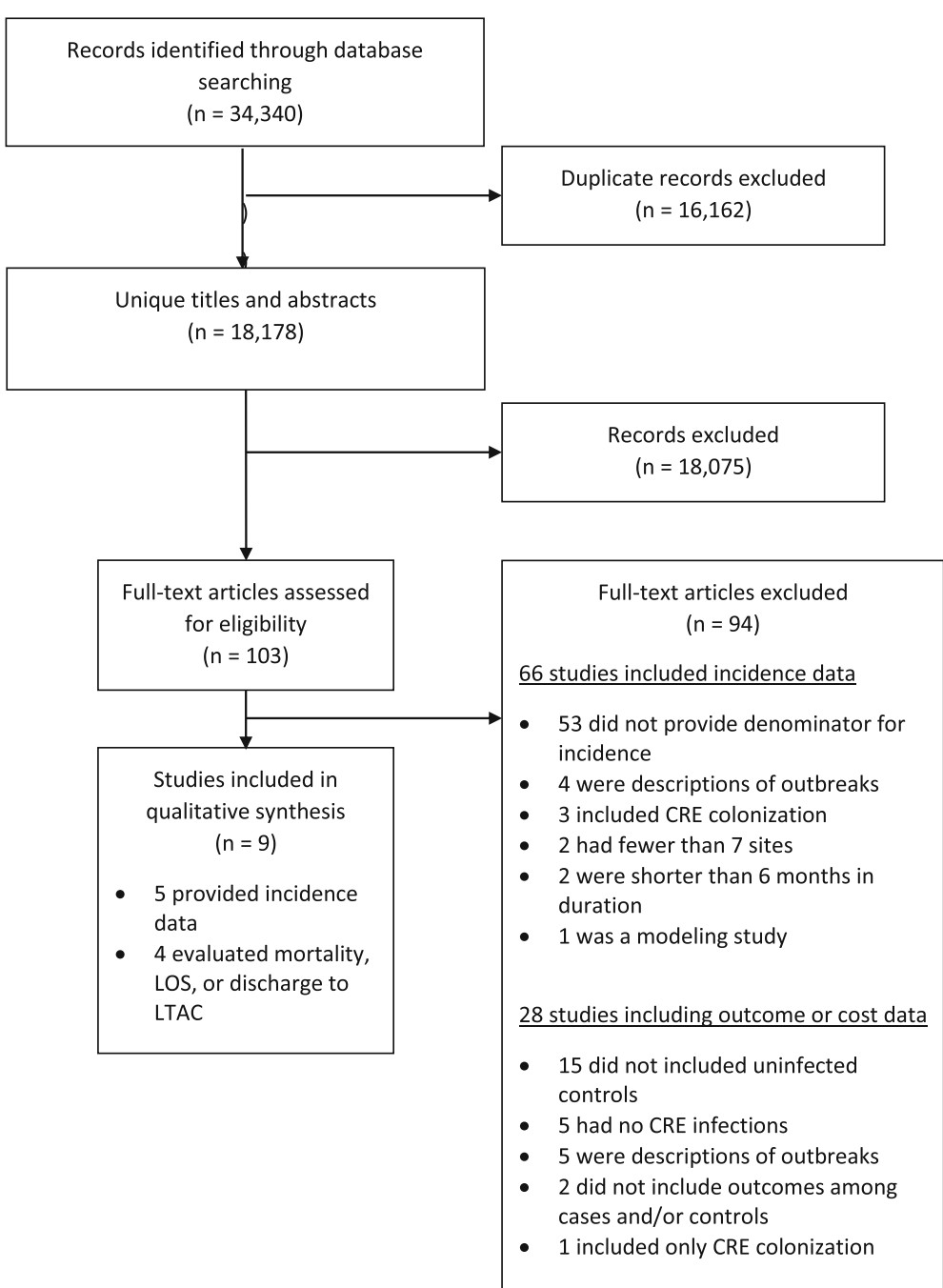

Fig. 1 Flow diagram of search strategy. Legend: CRE, Carbapenem-resistant Enterobacteriaceae; LOS, length of stay; LTAC, long-term acute-care hospital

bias in terms of adequacy of follow-up, cohort design and analysis, and assessment of outcomes.

\section{Incidence of CRE infections}

There were 5 studies (Table 2) that measured the incidence of CRE: 4 studies used the lower CLSI breakpoints (i.e. 2010 and later) [15-18] while one study largely used the pre-2010 breakpoints [19]. All studies included clinical cultures from sterile and non-sterile body sites, but one study limited non-sterile cultures to only urine samples [18].

Three studies used the denominator of patient-days $[15,17,19]$, but these 3 studies could not be pooled because definitions varied: 1 study included all species of Enterobacteriaceae while 2 studies used less inclusive definitions. Among these 3 studies, the incidence of CRE ranged from 0.46 CRE infections per 10,000 patient-days to $4.17 \mathrm{CRE}$ infections per 10,000 patient-days. Two studies stratified by long-term acute care (LTAC) hospitals and acute care hospitals [15, 17]. One of these studies-which took place in Los Angeles County, California-found that the incidence of CRE infections in acute care hospitals was 0.31 per 10,000 patients-days and the incidence of CRE infections in LTAC hospitals was 2.54 per 10,000 patient-days [17]. The other study, which took place in Michigan, found a similar incidence of CRE infections in LTAC hospitals (2.93 per 10,000 patient-days) but the incidence of CRE infections among the acute care hospitals (1.01 per 10,000 patient-days) was higher than that of the Los Angeles County study [15].

Two studies included both inpatients and outpatients, reflected in a denominator of person-years $[16,18]$. In a study of the civilian component of the US military health care system, the incidence of CRE remained steady at 0 . 49 infections per 100,000 person-years between 2005 
Table 1 Risk of bias assessment of CRE studies using Newcastle Ottawa tool (Stang 2010). Receiving a star $\left(^{*}\right)$ represents that the study has low risk of bias and high quality in that category

\begin{tabular}{|c|c|c|c|c|c|c|c|c|}
\hline \multirow[b]{2}{*}{$\begin{array}{l}\text { Author } \\
\text { (Year) }\end{array}$} & \multicolumn{4}{|l|}{ Selection } & \multirow{2}{*}{$\begin{array}{l}\text { Comparability } \\
\text { Comparability of } \\
\text { cohorts on the } \\
\text { basis of design } \\
\text { or analysis }\end{array}$} & \multicolumn{3}{|l|}{ Outcome } \\
\hline & $\begin{array}{l}\text { Representative-ness } \\
\text { of the exposed } \\
\text { cohort }\end{array}$ & $\begin{array}{l}\text { Selection of the } \\
\text { non-exposed } \\
\text { cohort }\end{array}$ & $\begin{array}{l}\text { Ascertainment } \\
\text { of exposure }\end{array}$ & $\begin{array}{l}\text { Demonstration that } \\
\text { outcome of interest } \\
\text { was not present at } \\
\text { start of study }\end{array}$ & & $\begin{array}{l}\text { Assessment } \\
\text { of outcome }\end{array}$ & $\begin{array}{l}\text { Was follow-up } \\
\text { long enough } \\
\text { for outcomes to } \\
\text { occur }\end{array}$ & $\begin{array}{l}\text { Adequacy } \\
\text { of follow-up } \\
\text { of cohorts }\end{array}$ \\
\hline $\begin{array}{l}\text { Bogan } \\
(2014) \\
{[20]}\end{array}$ & * & * & * & $*$ & * & * & * & - \\
\hline $\begin{array}{l}\text { Brennan } \\
\text { (2014) } \\
{[15]}\end{array}$ & * & * & * & * & - & - & - & - \\
\hline $\begin{array}{l}\text { Gasink } \\
(2009) \\
{[21]}\end{array}$ & * & * & * & * & * & * & * & - \\
\hline $\begin{array}{l}\text { Guh } \\
(2015) \\
{[18]}\end{array}$ & * & * & * & * & - & - & - & - \\
\hline $\begin{array}{l}\text { Lesho } \\
\text { (2015) } \\
{[16]}\end{array}$ & * & * & * & * & - & - & - & - \\
\hline $\begin{array}{l}\text { Marquez } \\
(2013) \\
{[17]}\end{array}$ & * & * & * & - & - & - & - & - \\
\hline $\begin{array}{l}\text { Patel } \\
\text { (2008) } \\
{[22]}\end{array}$ & * & * & $*$ & * & $*$ & * & * & - \\
\hline $\begin{array}{l}\text { Thaden } \\
\text { (2014) } \\
\text { [19] }\end{array}$ & * & * & * & * & - & - & - & - \\
\hline $\begin{array}{l}\text { Kalpoe } \\
(2012) \\
{[23]}\end{array}$ & * & * & $*$ & * & * & * & * & $*$ \\
\hline
\end{tabular}

and 2012; the peak incidence was 0.67 per 100,000 person years in the year 2010 [16]. A study across 7 metropolitan areas estimated an incidence of 2.94 cases per 100,000 persons in 2012 and 2.93 per 100,000 persons in 2013. Site-specific incidence rates ranged from 0.82 cases per 100,000 persons in Oregon to 4.80 cases per 100,000 persons in Maryland [18].

Carbapenemase production was assessed in 2 studies $[15,18]$. One study only included isolates with a positive or unknown result on the Modified-Hodge Test (MHT), but a breakdown of MHT results was not provided [15]. In another study, 90 of 188 (47.9\%) isolates across 6 sites produced a carbapenemase, all of which were KPCs [18].

\section{Outcomes attributable to CRE infections}

Each of the 5 outcomes studies included data from 2009 or earlier (Table 3). Two studies evaluated outcomes in CRE patients compared to uninfected controls [20, 23]. In the earliest study, all patients who underwent liver transplantation at a single center were followed for 1 year after transplantation [23]. That study found that $71 \%$ of the patients infected with carbapenem-resistant $K$. pneumoniae (CRKP) died compared to $14 \%$ of the uninfected patients (log rank $p<0.001)$. Based on a multivariate Cox proportional hazards analysis, mortality at 1year was significantly higher in patients who developed CRKP infections compared to uninfected patients (hazard ratio $=4.9,95 \%$ CI 1.5-15.6). In the second study, patients with and without infections were matched by hospital or facility, unit or clinic, calendar year, and time at risk (i.e., from admission to culture). This study found higher odds of dying among CRE patients compared with uninfected controls, but the difference was not statistically significant $(\mathrm{OR}=1.6 ; 95 \% \mathrm{CI}$ : 0.7-3.3) [20]. The study also found that CRE infected patients had significantly higher odds of being discharged to a LTAC after being admitted from home $(\mathrm{OR}=13.7$; 95\% CI: 4.3-44. 4). There was no difference in LOS between CRE and uninfected patients.

Three studies evaluated outcomes in patients with CRE compared to carbapenem-susceptible Enterobacteriaceae (CSE) [20-22]. Two studies only included isolates of $K$. pneumoniae while the third study included all types of CSE not producing extended- 
Table 2 Studies that Evaluated CRE Incidence

\begin{tabular}{|c|c|c|c|c|c|c|}
\hline $\begin{array}{l}\text { First Author } \\
\text { (Year) }\end{array}$ & Study Population & CLSI protocol & Study Period & Culture type & $\begin{array}{l}\text { \# of } \\
\text { Infections }\end{array}$ & IncidenceRate \\
\hline $\begin{array}{l}\text { Brennan (2014) } \\
\text { [15] }\end{array}$ & $\begin{array}{l}\text { CRE Surveillance and } \\
\text { Prevention Initiative } \\
\text { in Michigan }\end{array}$ & M100-S22 2012 & $09 / 2012-02 / 2013$ & $\begin{array}{l}\text { All cultures positive for carbapenem } \\
\text { non-susceptible K. pneumoniae or } \\
\text { E.coli. All cases had a positive or } \\
\text { unknown modified Hodge-Test } \\
\text { result. Only } 1 \text { case per patient } \\
\text { per } 30 \text {-day period. }\end{array}$ & 102 & $\begin{array}{l}\text { Per } 10,000 \\
\text { patient-days } \\
\text { Overall: } 1.07 \\
\text { Acute care: } 1.01 \\
\text { LTAC: } 2.93 \\
\text { East: } 1.24 \\
\text { West: } 0.52 \\
\text { Mid-North: } 0.36\end{array}$ \\
\hline $\begin{array}{l}\text { Lesho (2015) } \\
{[16]}\end{array}$ & $\begin{array}{l}\text { Tricare, i.e.civilian } \\
\text { component of the } \\
\text { US military health } \\
\text { care system }\end{array}$ & M100-S20-2010 & 01/2005-12/2012 & $\begin{array}{l}\text { All CRE-positive cultures } \\
\text { (E.coli, Klebsiella spp., Enterobacter spp.). } \\
\text { For each year of surveillance, the first } \\
\text { CRE-positive culture per patient was } \\
\text { included. }\end{array}$ & 368 & $\begin{array}{l}\text { Per 100,000 } \\
\text { person-years } \\
\text { All Years: } 0.487 \\
\text { 2012: } 0.394 \\
\text { 2011: } 0.528 \\
\text { 2010: } 0.672 \\
\text { 2009: } 0.607 \\
\text { 2008: } 0.439 \\
\text { 2007: } 0.424 \\
\text { 2006: } 0.490 \\
\text { 2005: } 0.335\end{array}$ \\
\hline $\begin{array}{l}\text { Marquez } \\
(2013)[17]\end{array}$ & Los Angeles County & M100-S20 2010 & 06/2010-05/2011 & $\begin{array}{l}\text { All cultures positive for } \\
\text { carbapenem-resistant } K \text {. pneumoniae. } \\
\text { Only } 1 \text { isolate allowed per patient } \\
\text { per calendar month. }\end{array}$ & 675 & $\begin{array}{l}\text { Per } 1000 \\
\text { patient-days } \\
\text { Acute and } \\
\text { LTAC: } 0.46 \\
\text { LTAC only: } 2.54 \\
\text { Acute only: } 0.31\end{array}$ \\
\hline $\begin{array}{l}\text { Thaden (2014) } \\
\text { [19] }\end{array}$ & $\begin{array}{l}\text { Duke Infection } \\
\text { Control Outreach } \\
\text { Network (DICON) }\end{array}$ & $\begin{array}{l}\text { M100-S20 } 2010 \\
\text { (20\%) sites; earlier } \\
\text { CLSI definitions } \\
\text { (80\% sites) }\end{array}$ & 01/2008-12/2012 & $\begin{array}{l}\text { All CRE-positive cultures. Only } 1 \\
\text { culture was allowed per patient } \\
\text { for the entire surveillance period. }\end{array}$ & 180 & $\begin{array}{l}\text { Per } 100,000 \\
\text { patient-days } \\
\text { 2008: } 0.26 \\
\text { 2012: } 1.4\end{array}$ \\
\hline $\begin{array}{l}\text { Guh (2015) } \\
{[18]}\end{array}$ & $\begin{array}{l}\text { Multi-site Gram-negative } \\
\text { Surveillance Initiative }\end{array}$ & M100-S22 2012 & $1 / 2012-12 / 2013$ & $\begin{array}{l}\text { All CRE non-susceptible cultures } \\
\text { (E.coli, Klebsiella spp., Enterobacter spp.) } \\
\text { from a normally sterile site or urine. } \\
\text { An incident case was defined as the } \\
\text { first isolate from a patient per 30-day } \\
\text { period. }\end{array}$ & 599 & $\begin{array}{l}\text { Per } 100,000 \\
\text { persons } \\
\text { 2012: } 2.94 \\
\text { 2013: } 2.93\end{array}$ \\
\hline
\end{tabular}

CLSI Clinical and Laboratory Standards Institute, CRE carbapenem-resistant Enterobacteriaceae, LTAC long-term acute-care hospital

spectrum beta-lactamases (ESBLs). Two studies used multivariable analysis to adjust for important predictors of mortality; only one of these studies adjusted for severity of illness [21] while the other matched cases-and-controls on baseline factors [20]. The third study matched patients with CRE to those with CSE based on body-site of infection [22].

In both studies that exclusively evaluated $K$. pneumoniae, cases with carbapenem-resistance had significantly higher odds of all-cause in-hospital mortality $(\mathrm{OR}=2.28$ and $\mathrm{OR}=3.71$; Table 3) $[21,22]$. One of these studies also found that the odds of attributable in-hospital mortality were more than 4-fold higher among CRKPinfected patients compared with carbapenem-susceptible K. pneumoniae infected controls [22]. In the study that included all types of Enterobacteriaceae, carbapenemresistance was not significantly associated with either an increase in hospital mortality (adjusted OR 2.7, 95\% CI 0.8-9.4) or a longer LOS. However, carbapenemresistance was associated with being discharged to a
LTAC after being admitted from home $(\mathrm{OR}=14.5$, 95\% CI 2.7-79.8).

\section{Discussion}

Estimating the incidence of CRE is an important step in designing a national public health response to this emerging pathogen [24]. Our review found that the reported incidence of CRE in the US was 0.3-2.93 infections per 100,000 person-years. The incidence of CRE is relatively higher in LTACs compared to acute-care hospitals and community settings. In 1 population-based study, nearly half of CRE isolates produced a carbapenemase. Carbapenemase-producing CRE are of the greatest epidemiologic concern, because these enzymes are typically carried on mobile genetic elements that can be shared with other bacteria [25].

Based on our findings, CRE is still relatively uncommon in the US compared to other antibiotic-resistant pathogens. For example, the estimated incidence of invasive methicillin-resistant Staphylococcus aureus (MRSA) 


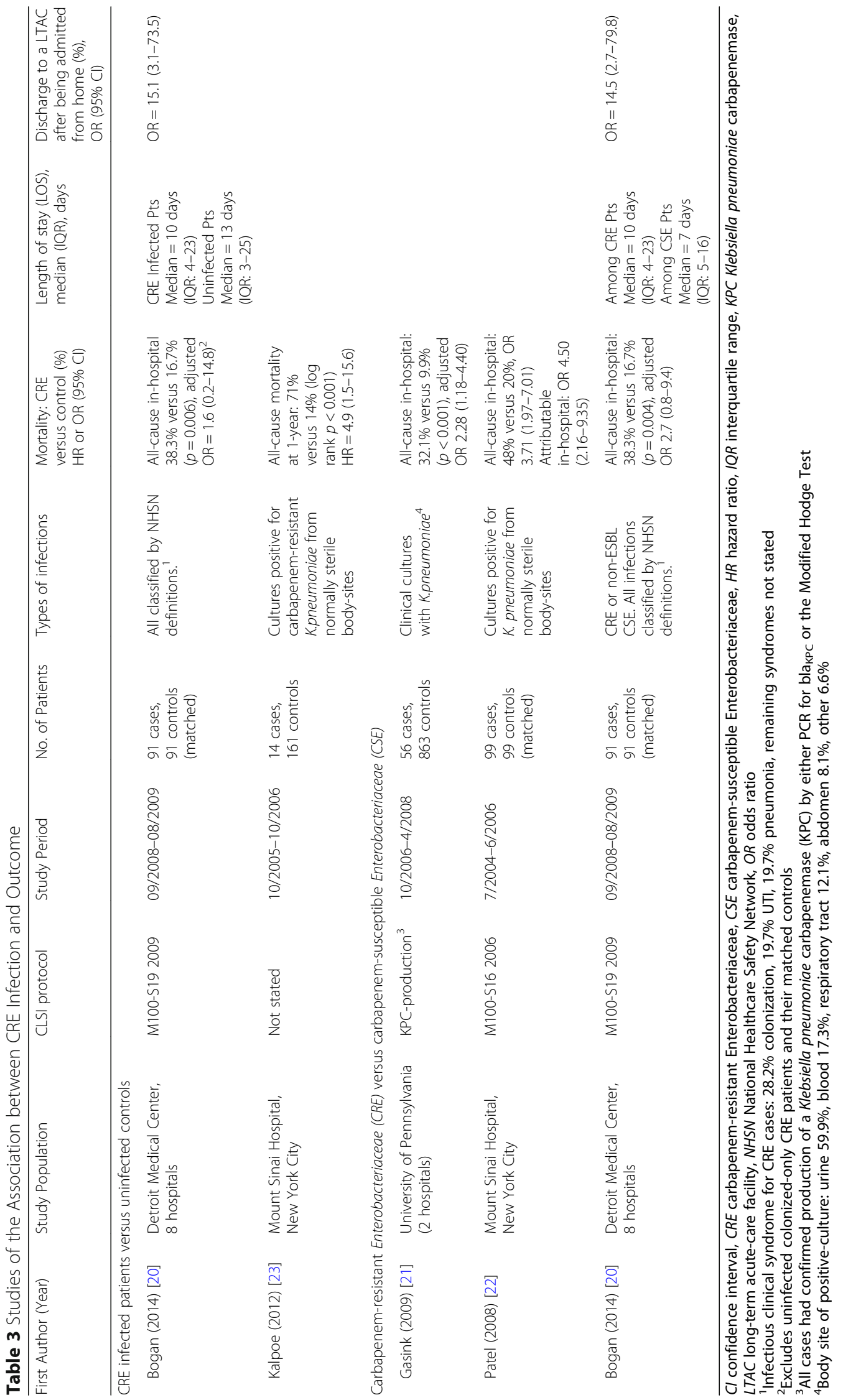


infections in 2011 across the US was 25 per 100,000 persons, or at least 8 times more common than CRE [26]. In the Veterans Health Administration during 20092013, the overall incidence of $C$. difficile was approximately 200 infections per 100,000 patient-years, which was at least 65 times more common than CRE [27]. It is important to note that, even though the current incidence of CRE is low, CRE has been rapidly spreading across the US. Prior to 1996, carbapenemase-producing CRE was not reported in the US, but as of August 2017, this pathogen has been reported in every US state but Idaho [28].

Despite its low incidence, CRE remains a public health threat due to its limited treatment options and worse clinical outcomes [1]. Based on the studies that compared outcomes between CRE and uninfected patients, infection with CRE was associated with a higher risk of being discharged to a LTAC and a higher risk of death within the year after liver transplantation [20, 23]. Studies consistently reported an unadjusted CRE-related mortality rate that was higher than the $6.6 \%$ estimate from the CDC [1].

Surprisingly, however, patients with CRE were not always found to have an increased risk for death compared with controls. Studies that compared CRE to uninfected patients reached different conclusions on mortality, albeit using different definitions of mortality [20, 23]. Conflicting results on mortality were also seen in studies that compared CRE to CSE. Two studies found that patients with carbapenem-resistant $K$. pneumoniae had 2-3 times the odds of in-hospital death as patients with carbapenem-susceptible $K$. pneumoniae, but a similar difference in mortality was not seen in a study that included all types of Enterobacteriaceae (i.e., CRE compared with CSE). In contrast, evidence from outside the United States shows increased mortality with CRE. A case-control study from Israel found that, after adjusting for severity of illness, patients with infections from carbapenem-resistant K. pneumoniae had 4 times the risk of death as patients infected with carbapenem-susceptible K. pneumoniae [29].

While it seems intuitive that CRE would be associated with worse outcomes, the lack of consistency across the literature raises several important questions about how CRE cases are defined and how CRE outcomes are measured. First, only 2 studies in this systematic literature review restricted cases to patients with CRE-positive cultures from normally sterile body sites. As a result, there is potential that patients colonized with CRE (i.e., a positive culture from a non-sterile site in the absence of signs or symptoms of infection) were included as "infected" cases. Such a misclassification bias could obscure differences in outcomes. As with any bacteria, the body site of infection is a key determinant of outcomes. A CRE bacteremia, for example, would be expected to have a higher mortality rate than a CRE urinary tract infection. In fact, a case-control study from Israel found that carbapenem-resistant $K$. pneumoniae bacteremia has an attributable mortality of $50 \%$, or 3 times the risk of death compared with non-bacteremic controls [30]. Second, patients with CRE may have a higher risk of death for reasons beyond the infection itself. For example, CRE-positive patients may have a higher burden of comorbidities and, due to these comorbidities, be more acutely ill when they do become infected. These factors were not adequately accounted for in all studies. Third, it is possible that outcomes other than mortality are worse in patients with CRE, but these alternate outcomes have gone unmeasured. For example, none of the studies measured hospital re-admissions and costs.

Another potential explanation for the conflicting mortality results is that the current studies were underpowered to find statistically significant results. Each of the 4 studies that evaluated mortality included fewer than 100 CRE-infected patients. In the future, larger well-designed studies should be performed to assess the association between CRE infection and mortality.

All the studies included in this systematic literature review evaluated outcomes before the Food and Drug Administration's (FDA) approval of ceftazidime-avibactam and meropenem-vaborbactam. Now that these new and potentially more efficacious agents are available, a reevaluation of CRE-related outcomes is warranted.

There are several limitations to our meta-analysis. First, definitions of CRE varied across studies. This discrepancy reflects differences in how each study chose to define a CRE case; it also reflects changes in the CDC's definition for CRE and the CLSI's breakpoints for carbapenem-resistance. The original CDC definition for CRE did not include ertapenem, which limited its sensitivity for detecting OXA-48-producing CRE. Furthermore, studies that used the pre-2010 CLSI guidelines to define carbapenem-resistance or evaluated just certain species of Enterobacteriaceae may have underestimated the true incidence of CRE [19, 31]. Thus, we were unable to pool data using meta-analytic techniques. Second, while we excluded studies that used surveillance cultures, clinical cultures reflecting colonization of a non-sterile site were not consistently distinguished from true infections. This may have resulted in an overestimation of the incidence of infection and an underestimation of the risk of mortality. Third, our incidence rates were derived from a limited number of geographic regions and not the entire US. However, 2 studies included multiple states, which should increase the generalizability of our findings. Fourth, outcome studies were limited in both number and quality. For example, 3 of the 4 studies involved $\leq 2$ hospitals, and only 1 adjusted for severity of illness, a key determinant of mortality. 


\section{Conclusions}

In conclusion, while the incidence of CRE infections in the United States remains low on a national level, the incidence is highest in LTACs. Several studies have measured the incidence of CRE, but the percentage of CRE that results from carbapenemase-production needs to be better defined. Studies assessing outcomes in CREinfected patients have been small and have reached conflicting results. Future research should measure a variety of clinical outcomes, should be adequately powered and should adequately adjust for confounders to better assess the full burden of CRE. Specifically, outcomes of CRE infections treated with recently FDA-approved antibiotics warrant further evaluation.

Without adequate studies measuring the burden of CRE infections, proper distribution of resources for research and prevention efforts will be impossible, thereby leaving patients vulnerable to this important emerging pathogen.

\section{Additional file}

Additional file 1: Search Methods. (DOCX $32 \mathrm{~kb}$ )

\section{Abbreviations}

CDC: Centers for Disease Control and Prevention; CLSI: Clinical and laboratory standards institute; CRE: carbapenem-resistant Enterobacteriaceae; CRKP: carbapenem-resistant K. pneumoniae; CSE: carbapenem-susceptible Enterobacteriaceae; KPC: Klebsiella pneumoniae carbapenemase; LOS: length of stay; LTCF: Iong-term care facility; MesH: Medical Subject Headings; MHT: Modified-Hodge Test; MIC: minimum inhibitory concentration; NHSN: National healthcare safety network

\section{Funding}

This study was funded by the Centers for Disease Control and Prevention, Safe Healthcare, Epidemiology, and Prevention Research Development (SHEPheRD) Program (contract 200-2011-42039 to M.S. and E.N.P.), by the VA Health Services Research and Development (HSR\&D) Career Development Awards (award 16-204 to D.J.L., award 11-215 to M.L.S., award 11-210 to R.N), and by the VA HSR\&D Centers of Innovation: Center for Comprehensive Access \& Delivery Research Evaluation (CIN 13-412, PI: E.N.P.)

\section{Availability of data and materials}

The datasets used and/or analyzed during the current study are available from the corresponding author on reasonable request.

\section{Authors' contributions}

Study design: all authors. Data collection and analysis: MLC, MLS, ECB, AEB, RN, ENP Study supervision: MLS, ENP. Manuscript writing: DJL, MLC. Manuscript review: all authors. All authors read and approved the manuscript.

\section{Ethics approval and consent to participate}

Not applicable

\section{Competing interests}

The authors declare that they have no competing interests.

\section{Publisher's Note}

Springer Nature remains neutral with regard to jurisdictional claims in published maps and institutional affiliations.

\section{Author details}

${ }^{1}$ Center for Comprehensive Access Delivery \& Research, lowa City VA Health Care System, lowa City, USA. ${ }^{2}$ Department of Internal Medicine, Carver College of Medicine, University of lowa, lowa City, USA. ${ }^{3}$ University of lowa College of Public Health, lowa City, USA. ${ }^{4}$ Hardin Library for the Health Sciences, University of lowa, lowa City, USA. ${ }^{5}$ Ruth Lilly Medical Library, Indiana University School of Medicine, Indianapolis, Indiana, USA. ${ }^{6}$ Veterans Affairs Salt Lake City Health Care System, Salt Lake City, Utah, USA.

${ }^{7}$ Department of Internal Medicine, University of Utah School of Medicine, Salt Lake City, Utah, USA.

Received: 26 January 2018 Accepted: 13 April 2018

Published online: 24 April 2018

\section{References}

1. Centers for Disease Control and Prevention. Antibiotic resistance threats in the United States. 2013; http://www.cdc.gov/drugresistance/threat-report2013/. Accessed 17 Jan 2018

2. Gupta N, Limbago BM, Patel JB, Kallen AJ. Carbapenem-resistant Enterobacteriaceae: epidemiology and prevention. Clin Infect Dis. 2011; 53(1):60-7.

3. Centers for Disease Control and Prevention. Facility Guidance for Control of Carbapenem-resistant Enterobacteriaceae (CRE): November 2015 Update CRE Toolkit. https://www.cdc.gov/hai/pdfs/cre/CRE-guidance-508.pdf. Accessed 17 Jan 2018

4. Molton JS, Tambyah PA, Ang BS, Ling ML, Fisher DA. The global spread of healthcare-associated multidrug-resistant bacteria: a perspective from Asia. Clin Infect Dis. 2013;56(9):1310-8.

5. van Loon K, Voor In't Holt AF, Vos MC. A systematic review and metaanalyses of the clinical epidemiology of carbapenem-resistant Enterobacteriaceae. Antimicrob Agents Chemother. 2018;62(1)

6. Sievert DM, Ricks P, Edwards JR, et al. Antimicrobial-resistant pathogens associated with healthcare-associated infections: summary of data reported to the national healthcare safety network at the centers for disease control and prevention, 2009-2010. Infect Control Hospital Epidemiology. 2013;34(1):1-14

7. Epstein L, Hunter JC, Arwady MA, et al. New Delhi metallo-beta-lactamaseproducing carbapenem-resistant Escherichia coli associated with exposure to duodenoscopes. JAMA. 2014;312(14):1447-55.

8. Gohil SK, Singh R, Chang J, et al. Emergence of carbapenem-resistant Enterobacteriaceae in Orange County, California, and support for early regional strategies to limit spread. Am J Infect Control. 2017;45(11):1177-82.

9. Ray MJ, Lin MY, Weinstein RA, Trick WE. Spread of carbapenem-resistant Enterobacteriaceae among Illinois healthcare facilities: the role of patient sharing. Clin Infect Dis. 2016;63(7):889-93.

10. Satlin MJ, Chen L, Patel G, et al. Multicenter clinical and molecular epidemiological analysis of bacteremia due to carbapenem-resistant Enterobacteriaceae (CRE) in the CRE epicenter of the United States. Antimicrob Agents Chemother. 2017;61(4)

11. Centers or Disease Control and Prevention. Guidance for Control of Carbapenem-resistant Enterobacteriaceae (CRE). https://stacks.cdc.gov/view/ cdc/13205. Accessed 17 Jan 2018.

12. Stroup DF, Berlin JA, Morton SC, et al. Meta-analysis of observational studies in epidemiology: a proposal for reporting. Meta-analysis of observational studies in epidemiology (MOOSE) group. JAMA. 2000;283(15):2008-12.

13. Moher D, Liberati A, Tetzlaff J, Altman DG, Group P. Preferred reporting items for systematic reviews and meta-analyses: the PRISMA statement. Ann Intern Med. 2009;151(4):264-9. W264

14. Stang A. Critical evaluation of the Newcastle-Ottawa scale for the assessment of the quality of nonrandomized studies in meta-analyses. Eur J Epidemiol. 2010;25(9):603-5.

15. Brennan BM, Coyle JR, Marchaim D, et al. Statewide surveillance of carbapenem-resistant enterobacteriaceae in Michigan. Infect Control Hosp Epidemiol. 2014;35(4):342-9.

16. Lesho EP, Clifford RJ, Chukwuma U, et al. Carbapenem-resistant Enterobacteriaceae and the correlation between carbapenem and fluoroquinolone usage and resistance in the US military health system. Diagn Microbiol Infect Dis. 2015;81(2):119-25.

17. Marquez P, Terashita D, Dassey D, Mascola L. Population-based incidence of carbapenem-resistant Klebsiella pneumoniae along the continuum of care, Los Angeles County. Infect Control Hosp Epidemiol. 2013;34(2):144-50. 
18. Guh AY, Bulens SN, Mu Y, et al. Epidemiology of carbapenem-resistant Enterobacteriaceae in 7 US communities, 2012-2013. JAMA. 2015; 314(14):1479-87.

19. Thaden JT, Lewis SS, Hazen KC, et al. Rising rates of carbapenem-resistant enterobacteriaceae in community hospitals: a mixed-methods review of epidemiology and microbiology practices in a network of community hospitals in the southeastern United States. Infect Control Hosp Epidemiol. 2014;35(8):978-83.

20. Bogan C, Kaye KS, Chopra T, et al. Outcomes of carbapenem-resistant Enterobacteriaceae isolation: matched analysis. Am J Infect Control. 2014; 42(6):612-20.

21. Gasink LB, Edelstein PH, Lautenbach E, Synnestvedt M, Fishman NO. Risk factors and clinical impact of Klebsiella pneumoniae carbapenemaseproducing K. Pneumoniae. Infect Control Hosp Epidemiol. 2009;30(12):1180-5

22. Patel G, Huprikar S, Factor SH, Jenkins SG, Calfee DP. Outcomes of carbapenem-resistant Klebsiella pneumoniae infection and the impact of antimicrobial and adjunctive therapies. Infect Control Hosp Epidemiol. 2008; 29(12):1099-106

23. Kalpoe JS, Sonnenberg E, Factor SH, et al. Mortality associated with carbapenem-resistant Klebsiella pneumoniae infections in liver transplant recipients. Liver Transpl. 2012;18(4):468-74.

24. Schwaber MJ, Lev B, Israeli A, et al. Containment of a country-wide outbreak of carbapenem-resistant Klebsiella pneumoniae in Israeli hospitals via a nationally implemented intervention. Clin Infect Dis. 2011;52(7):848-55.

25. Mathers AJ, Stoesser N, Sheppard AE, et al. Klebsiella pneumoniae carbapenemase (KPC)-producing K. Pneumoniae at a single institution: insights into endemicity from whole-genome sequencing. Antimicrob Agents Chemother. 2015:59(3):1656-63.

26. Dantes $R$, Mu Y, Belflower $R$, et al. National burden of invasive methicillinresistant Staphylococcus aureus infections, United States, 2011. JAMA Intern Med. 2013;173(21):1970-8.

27. Young-Xu Y, Kuntz JL, Gerding DN, et al. Clostridium difficile infection among veterans health administration patients. Infect Control Hosp Epidemiol. 2015;36(9):1038-45.

28. Centers for Disease Control and Prevention. Tracking CRE. 2017; https:// www.cdc.gov/hai/organisms/cre/trackingcre.html. Accessed 8 Dec 2017.

29. Schwaber MJ, Klarfeld-Lidji S, Navon-Venezia S, Schwartz D, Leavitt A, Carmeli Y. Predictors of carbapenem-resistant Klebsiella pneumoniae acquisition among hospitalized adults and effect of acquisition on mortality. Antimicrob Agents Chemother. 2008;52(3):1028-33.

30. Borer A, Saidel-Odes L, Riesenberg K, et al. Attributable mortality rate for carbapenem-resistant Klebsiella pneumoniae bacteremia. Infect Control Hosp Epidemiol. 2009;30(10):972-6.

31. Hombach M, Bloemberg GV, Bottger EC. Effects of clinical breakpoint changes in CLSI guidelines 2010/2011 and EUCAST guidelines 2011 on antibiotic susceptibility test reporting of gram-negative bacilli. J Antimicrob Chemother. 2012;67(3):622-32.

\section{Ready to submit your research? Choose BMC and benefit from:}

- fast, convenient online submission

- thorough peer review by experienced researchers in your field

- rapid publication on acceptance

- support for research data, including large and complex data types

- gold Open Access which fosters wider collaboration and increased citations - maximum visibility for your research: over $100 \mathrm{M}$ website views per year

At BMC, research is always in progress.

Learn more biomedcentral.com/submissions 